\title{
Assessing the Resistance of Red Raspberry (Rubus idaeus L.) Genotypes to Phytophthora fragariae var. rubi in Hydroponic Culture
}

\author{
J.A. Pattison ${ }^{1}$ \\ Department of Horticultural Sciences, Cornell University, New York State \\ Agricultural Experiment Station, Geneva, NY 14456
}

W.F. Wilcox ${ }^{2}$

Department of Plant Pathology, Cornell University, New York State Agricultural Experiment Station, Geneva, NY 14456

C.A. Weber ${ }^{3}$

Department of Horticultural Sciences, Cornell University, New York State Agricultural Experiment Station, Geneva, NY 14456

Additional index words. root rot, disease resistance, disease assay

\begin{abstract}
A hydroponic method was developed and tested for screening red raspberry genotypes for resistance to Phytophthora fragariae var. rubi, the most common causal agent of Phytophthora root rot in raspberry. Plants of 'Titan' and 'Encore' exhibited typical disease symptoms, with the latter developing significantly smaller stem lesions and fewer petiole lesions. The resistant cultivar, 'Latham', regenerated healthy root tissue from the crown and older-order roots after initial infection and necrosis of young roots and exhibited no other symptoms beyond minor leaf chlorosis. This component of the resistance reaction has not been documented previously. A segregating $F_{1}$ population from the cross of 'Latham' $x$ 'Titan' had a survival rate of $56 \%$ with $42 \%$ classified as resistant, exhibited minimal symptoms, and produced varying amounts of healthy root tissue. This screening method allows multiple observations of all plant tissues, including roots, under repeatable and definable growth chamber conditions. It should be useful for classifying the phenotype of individuals in segregating red raspberry populations to investigate the inheritance of Phytophthora root rot resistance using molecular markers.
\end{abstract}

Phytophthora root rot is a severe disease of red raspberry (Rubus idaeus L.) in nearly all temperate growing regions of the world and imposes significant limitations on production capacity in the absence of control (Duncan etal., 1987; Wilcox et al., 1993). Although multiple Phytophthora spp. are pathogenic on this crop, P. fragariae var. rubi Wilcox and Duncan is by far the most common cause of serious losses in both Europe and the Americas (Duncan et al., 1987; Wilcox, 1989; Wilcox et al., 1993;Wilcox and Latorre, 2002). The organism thrives in poorly drained soils that tend to remain at or near saturation for extended periods of time, thereby favoring the production and dispersal of asexual, biflagellate zoospores (Wilcox, 1989). Under cool and saturated soil conditions, the polycyclic biology of $P$. fragariae var. rubi results in a compounded rate of inoculum increase and rapid spread of disease on susceptible hosts (Erwin and Ribeiro, 1996).

\footnotetext{
Received for publication 30 Jan. 2004. Accepted for publication 15 Apr. 2004. Research conducted at the New York State Agricultural Experiment Station, Geneva, N.Y. Use of trade names does not imply endorsement of the products named or criticism of similar ones not named.

${ }^{1}$ Postdoctoral associate.

${ }^{2}$ Professor.

${ }^{3}$ Assistant professor. Corresponding author; e-mail
} caw34@cornell.edu.
Typical disease symptoms include reduced frequency of primocane emergence, unproductive or collapsing floricanes resembling those damaged by low winter temperatures, and stunting of apical growing regions. Foliar symptoms commonly expressed are chlorosis, interveinal and perimeter necrosis, and scorching. In advanced disease stages, the pathogen destroys most or all of the root system and colonizes the crown and lower stem region, producing a characteristic water-soaked lesion that advances acropetally (Wilcox, 1989). Recommended control programs involve an integrated approach using a combination of genetic host resistance, avoidance or amelioration of wet soils, and registered fungicides, although host resistance appears to be the most critical component (Heiberg, 1995; Maloney et al., 1993; Wilcox et al., 1999b). Several cultivars possess high levels of resistance including 'Latham', 'Asker' and 'Newburgh' (Barritt et al., 1979, 1981; Kennedy and Duncan, 1991; Levesque and Daubeny, 1999; Spiegler and Thoss, 1993), although inferior horticultural traits or inferior fruit quality relegate these to a minority of the planted acreage. Conversely, many commercially popular cultivars such as 'Titan', 'Lauren', 'and 'Willamette' possess insufficient resistance and succumb to disease over time. Consequently, there is a great need for root rot resistant material pos- sessing superior commercial and horticultural characteristics.

Barritt et al. (1979) found resistance to P. fragariae var. rubi to be highly heritable using parent offspring regression methods on field-grown parents and seedlings and proposed that significant additive genetic variation was responsible for the variation in the observed resistance levels. Later, Nestby and Heiberg (1995) in a different population and under greenhouse conditions found significantly lower estimates of $\mathrm{h}^{2}(0.21$ and 0.38 for disease index and percent survival, respectively) and significant effects for specific and general combining abilities. These conflicting results indicate that both additive and nonadditive genetic variation were contributing toward resistance and warrant further study. Wild raspberry species such as $R$. idaeus strigosus Michx. and $R$. spectabilis Pursh. have been used as sources of resistance, with the former speculated to have been the donor to 'Latham', the resistant standard (Bristow et al., 1988; Knight, 1991; Levesque and Daubeny, 1999). Red raspberry breeding populations traditionally are screened for root rot resistance in pathogen-infested field plots or under controlled greenhouse conditions (Barritt et al., 1979, 1981; Heiberg, 1995; Kennedy and Duncan, 1991; Laun and Zinkernagel, 1997; Nestby and Heiberg, 1995). Field screening has the advantage of providing a set of conditions that more closely mimics those of commercial production. However, the variability in the development of this disease, and the inherent variability in drainage and pathogen densities within many field sites, has led numerous investigators to use greenhouse techniques.

In the greenhouse, potted seedlings typically are grown in soil that has been infested with the pathogen and kept excessively wet with frequent irrigation and/or flooded to provide periods of standing water (Bristow et al., 1988; Heiberg, 1995; Kennedy and Duncan, 1991; Laun and Zinkernagel, 1997; Wilcox et al., 1999a). Flooding duration can greatly influence the reaction of several red raspberry cultivars to $P$. fragariae var. rubi (Duncan and Kennedy, 1989). Under an excessive irrigation treatment and without flooding, some cultivars exhibited a response intermediate between symptom free and dead. However, when the same cultivars were exposed to a single 24-h flooding treatment, the intermediate reaction disappeared and these same cultivars died (Wilcox et al., 1999a). Laun and Zinkernagel (1993) suggested using larger plant and pot sizes for assessing intermediate reactions of cultivars. However, when screening thousands of seedlings in a breeding program, greenhouse materials and space are expensive and limited. Thus, there is a need for a cost-effective means for evaluating the resistance of red raspberry genotypes to phytophthora root rot that can differentiate an intermediate reaction and reduce environmental variability. Hydroponic culture offers the ability to regularly observe the root and crown tissues of red raspberry plants challenged with $P$. fragariae var. rubi and has the potential for providing optimum growth conditions for both pathogen and host. Therefore, the 
Table 1. Plant disease index for assessing susceptibility of red raspberry genotypes following inoculation with Phytophthora fragariae var. rubi.

\begin{tabular}{ll}
\hline Score & Symptoms \\
\hline 0 & No root rot, no shoot symptoms \\
1 & Slight root rot, no shoot symptoms \\
2 & Slight root rot, slight shoot symptoms \\
3 & Moderate root rot, moderate shoot symptoms \\
4 & Severe root rot, severe shoot symptoms with the presence of living crown tissue \\
5 & Perennial crown dead \\
\hline
\end{tabular}

objective of the current research was to design a phytophthora root rot screening procedure that could 1) reduce environmental variability (i.e., temperature, light, and rhizosphere moisture), 2) identify an intermediate reaction, and 3) classify the phenotype of standard cultivars consistently, compared to previous reports of their resistance levels.

\section{Methods and Materials}

Hydroponic apparatus. A plastic storage container (Rubbermaid, Wooster, Ohio) measuring $51 \times 36 \times 20 \mathrm{~cm}$, with an approximate volume of $38 \mathrm{~L}$ served as the hydroponic basin. The fitted lid had 35 evenly distributed $4 \mathrm{~cm}$ holes for planting. Presoaked, sterilized rockwool substrate cubes $\left(\approx 4 \mathrm{~cm}^{3}\right)$ secured the plant crowns into the holes. Roots were grown submerged in $28 \mathrm{~L}$ of half strength Peter's Professional Hydro-Sol 5-11-26 nutrient solution (W.R. Grace \& Co., Fogelsville, $\mathrm{Pa}$.), supplemented with $10 \mathrm{~mm} \mathrm{Ca}\left(\mathrm{NO}_{3}\right)_{2}$ and maintained at $\mathrm{pH}$ 6.5. Two air stones, placed equidistant from each other and the basin sides, were connected by plastic tubing to a single aquarium-style air pump. Two $1.7-\mathrm{m}^{2}$ growth chambers were programmed with a 16-h day length at a constant $20{ }^{\circ} \mathrm{C}$ to accommodate the five experimental basins.

Plant material. Small plug plants of three red raspberry cultivars, derived from tissue culture and propagated in a greenhouse to minimize potential contamination with $P h y$ tophthora spp., were obtained from a commercial nursery (Nourse Farms, Whatley, Mass.). 'Latham' ('King' $\times$ 'Loudon'), 'Encore' ('Canby' $x$ 'Cherokee'), and 'Titan' ['Hilton' × NY598 ('Newburg' × 'St. Walfried')] were chosen to provide standards for the resistant, intermediate, and susceptible reaction types, respectively, based on observations in replicated field plots in Geneva, N.Y., or previous published studies (Barritt et al., 1981; Wilcox et al., 1999a). In total, $51 \mathrm{~F}_{1}$ individuals derived from a 'Latham' $x$ 'Titan' cross were also screened separately. The $F_{1}$ seeds were scarified in concentrated sulfuric acid for 20 minutes, washed with tap water and soaked in a $2.85 \%$ solution of calcium hypochlorite (w:v) with excess calcium hydroxide for $7 \mathrm{~d}$. Treated seeds were washed for 5 min under tap water and then stratified in moist vermiculite for eight weeks at $4{ }^{\circ} \mathrm{C}$. After stratification, seeds were sown in a soil-less medium containing peat and vermiculite (1.2:1) supplemented with $10 \mathrm{~N}-5 \mathrm{P}-10 \mathrm{~K}$ fertilizer and placed in a greenhouse under supplemental light to provide a 14-h photoperiod. Once most seedling plants developed two to three true leaves, root systems were washed under running tap water and soaked in a dilute solution of antibacterial soap for $15 \mathrm{~min}$ and trimmed to about $6 \mathrm{~cm}$. Cultivar plants received similar root cleaning and pruning. The $\mathrm{F}_{1}$ population was evaluated in two separate basins with each containing randomly planted resistant and susceptible check cultivars ('Latham and 'Titan', respectively). Empty holes in both the $\mathrm{F}_{1}$ and cultivar basins were closed using rockwool cubes.

Inoculation. Two pathogenic isolates of Phytophthora fragariae var. rubi, ATCC 16184 (M14) and NY588, were obtained from Peter Bristow at Washington State University and from one of our WFW collections, respectively. Isolates were maintained on solidV-8 agar plates as described by Wilcox et al. (1993). Inoculum was produced by growing the isolates separately in clarified V-8 broth for 14 to $21 \mathrm{~d}$ as described by Bristow et al. (1988). Mycelial mats were collected from the two to three week old liquid cultures into a Buchner funnel, washed with tap water, blotted dry and weighed. Mycelium from each isolate was comminuted separately in a Waring blender for two consecutive five-second pulses in about $500 \mathrm{~mL}$ of filter sterilized deionized water. Each hydroponic basin was inoculated with a suspension containing two grams of mycelium of each isolate when plants reached between 15 to $20 \mathrm{~cm}$ in height. Aeration was withheld for $48 \mathrm{~h}$ after inoculation. The nutrient solution was sampled weekly for the presence of zoospores by transferring $5-\mathrm{mL}$ aliquots into $15-\mathrm{mL}$ centrifuge tubes and vortexing for $1 \mathrm{~min}$. A microscope was used to count zoospores in a $0.1-\mu \mathrm{L}$ sample of the vortexed solution in a hemocytometer.

Disease assessment and statistical analysis. Disease symptoms were assessed on each plant $30 \mathrm{~d}$ postinoculation using four different criteria: 1) A qualitative plant disease index score ( 0 to 5 ) assigned on the basis of both root and shoot symptoms (Table 1); 2) stem lesion length; 3 ) the incidence of petioles with lesions; and 4) a root regeneration score $(0$ to 3 ), where $0=$ no new root production and original roots and crown necrotic, $1=$ no to few new roots produced but original root and crown tissue healthy, $2=$ moderate production of new root tissue, and $3=$ vigorous production of new root tissue.

Table 2. Reaction of red raspberry cultivars evaluated for susceptibility to Phytophthora fragariae var. rubi grown in hydroponic culture

\begin{tabular}{lcccc}
\hline & $\begin{array}{c}\text { Plant } \\
\text { disease } \\
\text { index } \\
(0-5)^{\mathrm{z}}\end{array}$ & $\begin{array}{c}\text { Stem } \\
\text { lesion } \\
(\mathrm{cm})^{\mathrm{z}}\end{array}$ & $\begin{array}{c}\text { Petiole } \\
\text { lesion } \\
\text { incidence } \\
(\%)^{\mathrm{z}}\end{array}$ & $\begin{array}{c}\text { Root } \\
\text { regeneration } \\
\text { index } \\
(0-3)^{\mathrm{z}}\end{array}$ \\
Cultivar & $1.5 \mathrm{a}$ & $0 \mathrm{a}$ & $15 \mathrm{a}$ & $2.5 \mathrm{a}$ \\
'Latham' & $4.4 \mathrm{~b}$ & $5.0 \mathrm{~b}$ & $50 \mathrm{~b}$ & $0 \mathrm{~b}$ \\
'Encore' & $4.7 \mathrm{~b}$ & $9.8 \mathrm{c}$ & $87 \mathrm{c}$ & $0 \mathrm{~b}$ \\
\hline
\end{tabular}

${ }^{2}$ Values represent the means from three replicate hydroponic basins with six plants of each cultivar per replication. Mean values not followed by a common letter are significantly different (Fisher's LSD, $P=0.05$ ). 

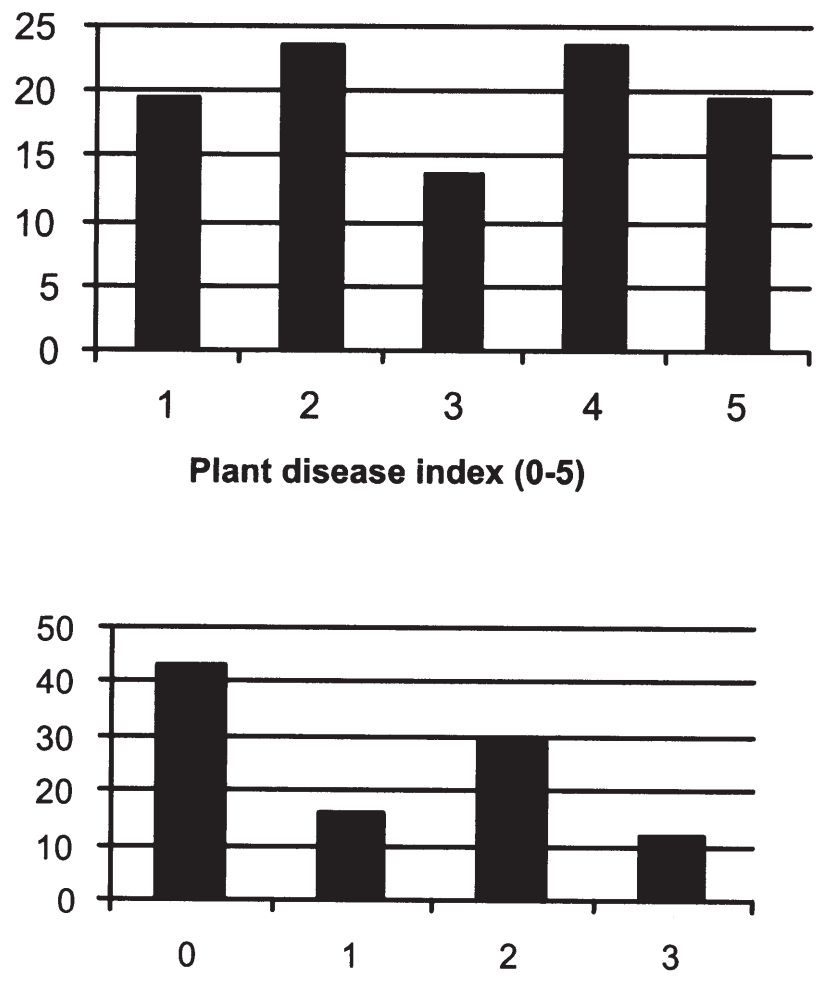

Root regeneration score (0-3)
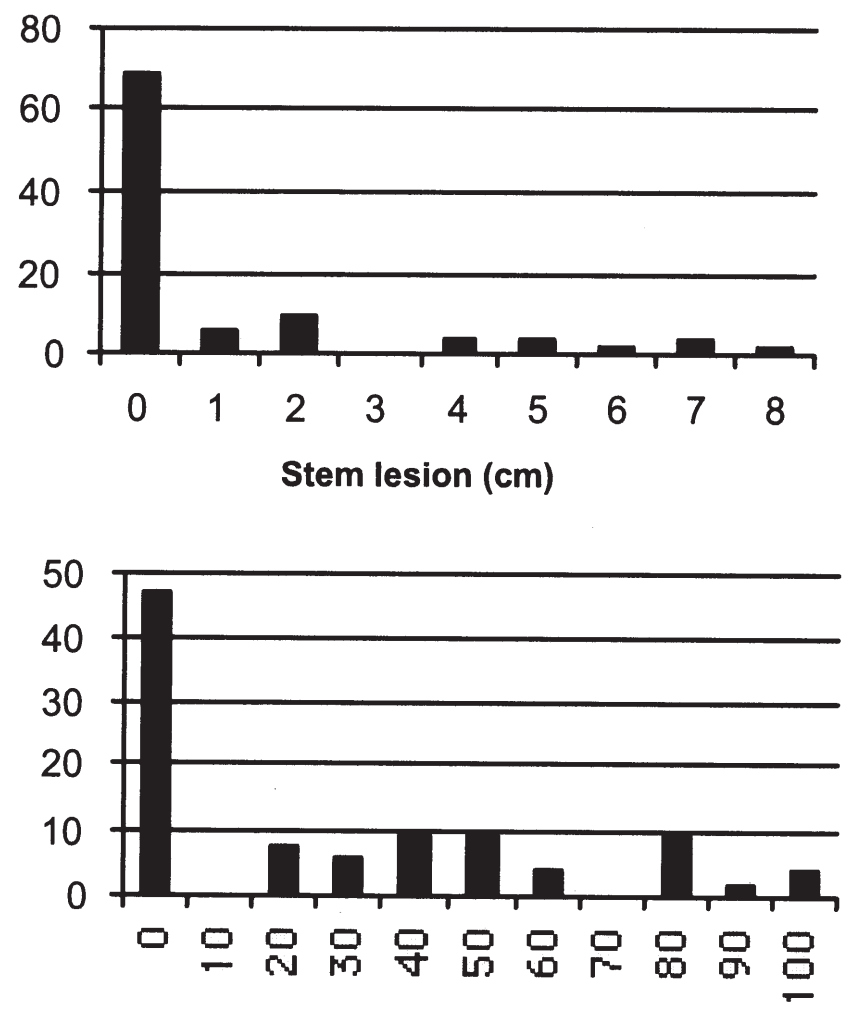

Percent petiole lesions

Fig. 1. Frequency distributions of an $\mathrm{F}_{1}$ population ('Latham' $\times$ 'Titan', $\mathrm{n}=51$ ) with respect to the four criteria used to evaluate the susceptibility to Phytophthora fragariae var. rubi in hydroponic culture.

moderate foliar symptoms, retention of healthy crown and older root tissues, and limited to absent production of new roots. Two-thirds of the seedlings showed no stem lesions with the remaining individuals distributed evenly across a wide range of lesion length categories. Nearly $50 \%$ of the $\mathrm{F}_{1}$ population had an incidence of petiole lesions $\leq 10 \%$ (Fig. 1).

In the cultivar test, differences attributable to blocks were nonsignificant for all criteria, indicating that consistent phenotype classification of red raspberry genotypes can be accomplished even when populations, selections, or cultivars need to be tested in multiple basins. Correlation analysis among the four different assessment criteria, using all genotypes tested (including the $\mathrm{F}_{1}$ population), showed a very strong negative relationship between the plant disease index and root regeneration score (Table 3). Stem lesion length and petiole lesion frequency also showed highly significant but less pronounced associations with plant disease index values.

\section{Discussion}

The hydroponic system for assessing the reactions of red raspberry genotypes to $P$. fragariae var. rubi allowed for multiple, nondestructive observations of all tissues, including roots, on plants maintained under repeatable and uniform conditions of temperature, rhizosphere moisture, inoculum, and light. It produced results consistent with previous greenhouse and field tests (Barritt et al., 1979, 1981; Kennedy and Duncan, 1991;
Laun and Zinkernagel, 1993; Levesque and Daubeny, 1999; Wilcox et al., 1999a) and allowed us to determine a reaction intermediate between resistant and susceptible. Advantages of this system include repeatability of environmental parameters throughout the year, reduced spatial needs for plant evaluation and the ability to periodically observe the development of disease symptoms on the roots and crown. Thus, it should be useful not only for the identification of resistant genotypes to be used in red raspberry breeding but also in more fundamental studies of this specific host $\times$ pathogen interaction.

We were able to observe a potentially significant component of the resistant reaction not documented previously. Although roots of 'Latham' and resistant $\mathrm{F}_{1}$ genotypes became diseased shortly after exposure to the pathogen, these individuals limited the initial infection, excluded disease from older root tissue and subsequently regenerated healthy roots, which remained symptom free throughout the experiment. This suggests that resistance to $P$. fragariae var. rubi may be an induced defense response in red raspberry. Symptoms on the shoots of resistant phenotypes were limited to only minor leaf chlorosis and minimal petiole lesions and may have resulted merely from the initial infection event and subsequent reduction of young feeder roots. Previous reports have associated minor foliar symptoms and root rot, the absence of stem lesions and minimal formation of oospores in root tissue among resistant red raspberry genotypes (Barritt et al., 1979; Heiberg, 1995; Laun and Zinkernagel, 1993, 1997; Kennedy and Duncan, 1991).

'Encore' has exhibited an intermediate to susceptible field reaction to phytophthora root rot in extensive field trials at Geneva, N.Y. In the hydroponic system, 'Encore' became diseased and the perennial crown of most plants died. However, stem lesion severity and the frequency of petiole lesions were less than on the susceptible standard, 'Titan'. Another factor potentially influencing the expression of partial field resistance in 'Encore' is its propensity to regenerate new primocanes from differentiated root tissue (suckers). 'Titan' predominately produces primocanes from existing crown tissue with minimal suckering, whereas 'Encore', exhibits a much greater propensity

Table 3. Correlation coefficients (r) between the different criteria used to evaluate 'Latham', 'Encore', 'Titan' and $51 \mathrm{~F}_{1}$ genotypes for susceptibility to $P$. fragariae var. rubi

\begin{tabular}{lcccc}
\hline $\begin{array}{l}\text { Evaluation } \\
\text { parameter }\end{array}$ & $\begin{array}{c}\text { Plant } \\
\text { disease } \\
\text { index }\end{array}$ & $\begin{array}{c}\text { Root } \\
\text { regeneration } \\
\text { score }\end{array}$ & $\begin{array}{c}\text { Stem } \\
\text { lesion } \\
\text { length }\end{array}$ & $\begin{array}{c}\text { Percent } \\
\text { petiole } \\
\text { lesions }\end{array}$ \\
\hline Plant disease index & 1 & & & \\
Root regeneration score & -0.94 & 1 & 1 & 1 \\
Stem lesion $(\mathrm{cm})$ & 0.64 & -0.58 & 0.78 & 1 \\
Percent petiole lesions & 0.77 & -0.70 & & \\
\hline
\end{tabular}


to produce root derived primocanes (Maloney et al., 1998; Sanford et al., 1985). This may allow such plants to effectively recover from individual infection events in the field when disease development is limited by environmental conditions (e.g., unfavorable soil moisture and/or temperature). However, under the high disease pressure imposed throughout this study, 'Encore' was unable to regenerate healthy root tissue and suffered severe crown rot.

Basing the relative susceptibility to phytophthora root rot on only one symptom of the disease, such as the presence or absence of a stem lesion, may not adequately represent the response to all other symptoms. For example, several $\mathrm{F}_{1}$ individuals had moderate to severe symptoms occurring on crowns and roots, and leaves, yet failed to manifest stem lesions. Secondary foliar symptoms of root rot including chlorosis, interveinal necrosis, and marginal scorching, likely result from rot induced reductions of root surface area, but also are symptomatic of nutrient deficiencies in the absence of disease (Wilder and Strik, 1991). Therefore, a quantitative evaluation of root system necrosis would appear to provide the most direct measure of a raspberry plant's response to Phytophthora sp. However, quantifying numbers of infected roots among large numbers of individuals may be prohibitively labor intensive, and is not an option in nonhydroponic systems. Given the strong correlation between root regeneration index and plant disease index, which together evaluate both primary and secondary symptom expression, selection for high levels of root rot resistance may be best accomplished using both criteria. Alternatively, stem lesion severity and the frequency of petiole lesions may be useful traits to investigate when the objective of selection is to distinguish among those cultivars or seedlings that possess intermediate levels of resistance.
The repeated, nondestructive examination of this host $\times$ pathogen interaction has identified a possible pathogen-induced resistance response, which merits further investigation. Future research will use this method to classify the phenotype of individuals in segregating populations to help aid in understanding the inheritance of root rot resistance through the use of molecular markers.

\section{Literature Cited}

Barritt, B.H., P.C. Crandall, and P.R. Bristow. 1979. Breeding for root rot resistance in red raspberry. J. Amer. Soc. Hort. Sci. 104:92-94.

Barritt, B.H., P.C. Crandall, and P.R. Bristow 1981. Red raspberry clones resistant to root rot. Fruit Var. J. 35:60-62.

Bristow,P.R., H.A. Daubeny, T.M. Sjulin, H.S.Pepin, R. Nestby, and G.E. Windom 1988. Evaluation of Rubus germplasm for reaction to root rot caused by Phytophthora erythroseptica. J. Amer. Soc. Hort. Sci. 113:588-591.

Duncan, J., D. Kennedy, and E. Seemuller 1987. Identities and pathogenicities of Phytophthora spp. causing root rot of raspberry. Plant Pathol. 36:276-289.

Duncan, J.M. and D.M. Kennedy. 1989. The effect of waterlogging on phytophthora root rot of red raspberry. Plant Path. 38:161-168.

Erwin, D.C. and O.K. Ribeiro. 1996. Introduction to the genus Phytophthora,p. 1-7. In: Phytophthora diseases worldwide. Amer. Phytopathol. Soc. Press, St. Paul, Minn.

Heiberg, N. 1995. Resistance to raspberry root rot (Phytophthora fragariae var. rubi) in red raspberry cultivars. Norwegian J. Agr. Sci. 9:41-47.

Kennedy, D.M. and J.M. Duncan. 1991. Methods for assessing the resistance of raspberry genotypes to phytophthora root rot. Plant Pathol. 40:387-394.

Knight, V.H. 1991. Use of the salmonberry Rubus spectabilis Pursh. in red raspberry breeding. J. Amer. Soc. Hort. Sci. 66:575-582.

Laun, N. and V. Zinkernagel. 1997. A comparison of the resistance against Phytophthora fragariae var. rubi, the causal agent of raspberry root rot. Phytopathology 145:197-204.

Laun, N. and V. Zinkernagel. 1993. Methods of screening raspberries for resistance to phytophthora root rot. Acta Hort. 352:569-578.

Levesque, C.A. and H.A. Daubeny. 1999. Variation in reaction to Phytophthora fragariae var. rubi in raspberry genotypes. Acta Hort. 505:231-235.

Maloney, K., E. Reich, and J. Sanford. 1998. 'Encore' red raspberry. N.Y. Food Life Sci. Bul. 152.

Maloney, K., W.F. Wilcox, and J.C. Sanford. 1993. Raised beds and metalaxyl for controlling phytophthora root rot in red raspberries. HortScience. 28:1106-1108.

Nestby, R. and N. Heiberg. 1995. Genetic variation for resistance to Phytophthora fragariae var. rubi in red raspberries. Euphytica 81:143-149.

Sanford, J., D. Ourecky, and J. Reich. 1985. 'Titan' red raspberry. HortScience 20:1133-1134.

Spiegler, G. and H. Thoss. 1993. Breeding for resistance to phytophthora root rot in red raspberries. Acta Hort. 352:477-484.

Wilcox, W.F. 1989. Identity virulence and isolation frequency of seven Phytophthora spp. causing root rot of raspberry in New York State. Phytopathology 79:93-101.

Wilcox, W.F., P.H. Scott, P.B. Hamm, D.M. Kennedy, J.M. Duncan, C.M. Brasier, and E.M. Hansen. 1993. Identity of a Phytophthora species attacking raspberry in Europe and North America. Mycol. Res. 97:817-831

Wilcox, W.F., J.R. Nevill, and J.A. Burr. 1999a. Susceptibility of red, black and purple raspberry cultivars to three Phytophthora species under greenhouse and field conditions. Acta. Hort.505:241-247.

Wilcox, W.F., M.P. Pritts, and M.J. Kelly. 1999b. Integrated control of Phytophthora root rot of red raspberry. Plant Dis. 83:1149-1154.

Wilcox, W.F. and B.A. Latorre. 2002. Identities and geographic distributions of Phytophthora spp. causing root rot of red raspberry in Chile. Plant Dis. 86:1357-1362.

Wilder, K. and B.C. Strik.1991. Disorders aused by abiotic factors, p. 79-80. In: M. Ellis, R. Converse, R. Williams, and B. Williamson (eds.). Compendium of raspberry and blackberry diseases and insects. Amer. Phytopathol. Soc. Press, St. Paul, Minn. 